
\title{
25 Research Square \\ Bone Regeneration and Repair: The Negative Influence of Positive Charge
}

\section{Lin $\mathrm{He}$}

Department of Orthopedic of Children's Hospital of Chongqing Medical University

\section{Yingling Yao}

Department of Orthopedic of Children's Hospital of Chongqing Medical University

\section{Nan Wang}

Department of Orthopedic of Children's Hospital of Chongqing Medical University

Guoxin Nan ( $\nabla$ ngx400879@163.com )

Department of Orthopedic of Children's Hospital of Chongqing Medical University

\section{Article}

Keywords: positive charge, negative charge, fracture, nonunion

Posted Date: April 5th, 2022

DOI: https://doi.org/10.21203/rs.3.rs-1383507/v2

License: (c) (1) This work is licensed under a Creative Commons Attribution 4.0 International License. Read Full License 


\section{Abstract}

Fracture nonunion is a common and challenging complication. Studies have reported that direct current stimulation can promote fracture healing, but there are reports that there are differences in cell density near positive and negative electrodes during direct current stimulation. The purpose of this study is to explore the effect of direct current positive and negative electrodes on the proliferation of osteoblasts and the effect on fracture healing in vivo. In vitro, MC3T3-E1 cells were stimulated by positive and negative charge to observe cell proliferation, apoptosis and osteogenic factor expression. In vivo, after the model of double toes fracture in New Zealand white rabbits was built, positive and negative charge were respectively connected to Kirschner Wires of fractures. DR examination was performed on Day 1, Day 15 and Day 30 to observe the fracture healing. All rabbits were killed after the last examination, the bone tissue samples were analyzed histologically. The results showed that compared with the control group, after DC stimulation, the number of cells near the positive electrode decreased significantly $(P<0.05)$, apoptosis increased $(P<0.05)$, osteocalcin, osteoblast specific gene and osteonectin decreased significantly near the positive electrode $(P<0.05)$, and increased significantly at the negative electrode $(P$ $<0.05)$. The fracture at the positive electrode junction of New Zealand white rabbits did not heal. Histomorphological analysis showed that there were more bone trabeculae and calcified bone in the bone tissue sections of the control group and the negative electrode than at the positive electrode. The thickness of bone trabeculae was thick and the connection was good. Positive charge inhibit the cell proliferation of osteoblasts; the fracture site with positive charge is not favor of fracture healing. The positive charge near the fracture site may be a reason for fracture nonunion.

\section{Introduction}

Bone tissue has strong potential of regeneration and repair. However, fracture nonunion often occurs, the most common reasons include infection, instability of fixation, and poor blood supply of fracture site et al [1-2]. Bone tissue repair and reconstruction involves complex biological and biomechanical mechanisms, which requires comprehensive effects of bone marrow mesenchymal stem cells, osteoblasts, osteoclasts and other cells in impaired area. High-intensity mechanical strain stimulation and endogenous current play an important role in bone growth [3]. Researchers have found that the epiphyseal region of the long bones is electronegative, and the whole shaft is electroneutral. When the fracture occurs, the electronegativity of the epiphyseal region became more negative, the charge of fracture site became negative, and this electronegative change maintained until the fracture healing [4]. The electronegativity trend and cytokines after fracture affect cell proliferation, migration, differentiation and osteogenesis. So, when the environment of fracture site become electropositive, will it lead to changes in these cellular activities? The goal of the present study is to verify our hypothesis.

\section{Methods}

\section{Cell culture}


MC3T3-E1 murine preosteoblastic cell lines were supplied from Orthopaedic laboratory of Army Medical University.Cells were cultured in Alpha Modified Eagles Medium (a-MEM, Hyclone,USA) containing 10\% fetal bovine serum(FBS,Gicbo,USA) and $1 \%$ antibiotic and antimycotic solution. Cells were incubated at $37^{\circ} \mathrm{C}, 5 \% \mathrm{CO} 2$, and atmospheric $\mathrm{O}_{2}$ concentration. In the experiments, cells were seeded into six-well plates at the density of 300,000 cells per well and the media volume was kept at $3 \mathrm{ml}$. Media change was carried out on the following day after seeding before applying electrical stimulation.

\section{Stabilized Electro Stimulation System Setup}

The DC stimulation chamber was used in this study was improved based on the original design of Mobini and Leppik etc[6].The current output terminal was powered by six $1.5 \mathrm{~V}$ batteries. The circuit integrates an adjustable buck regulator power supply module ( LM2596S ) to keep the output voltage constant and increase or decrease the resistance component through the required current. The current output terminal connects a wiring terminal fixed on the side of the 6-hole cover. The middle line of each hole was drilled on the 6 - hole plate cover, so that the distance between the two holes was $30 \mathrm{~mm}$. The titanium alloy wire ( $0.8 \mathrm{~mm}$ in diameter ) was used as the implanted electrode, and the effective length of the implanted electrode was $20 \mathrm{~mm}$. The electrode was paralleled with silver-coated copper cable, and the loose end of the copper wire was connected to the wiring end on the left side of the 6 - hole plate cover. The six-hole plate for cell inoculation is processed to communicate between the parallel holes. The schematic and physical drawings of the device are shown in Fig.1.

\section{Cell proliferation}

MC3T3-E1 cells were stimulated with direct current for 24 hours and 48 hours. Control group cells cultured without electrical stimulation. Collecting cells of anode, cathode, and control separately. The cells were made into a cell suspension during counting. The cell suspension was mixed with $0.4 \%$ trypan blue(Gicbo;catalog\#15250061,USA) at a ratio of 9:1, and 20uL was added to the countstar counting plate and observed under the microscope, the dead cells are stained obviously blue, while the live cells are colorless and transparent,count the number of live cells within 3 minutes.

\section{Apoptosis}

After 24 and $48 \mathrm{~h}$ of electrical stimulation, each group of cells was collected and the cell concentration was adjusted to $1 * 106 / \mathrm{mL}$. Following the procedure of the apoptosis assay kit (BD Biosciences,USA), the cells were resuspended in $5 \mathrm{~mL}$ flow tubes, $5 \mathrm{uL}$ of FITC-Annexin $\mathrm{V}$ and $5 \mathrm{uL}$ of PI staining solution were added to the flow tubes, mixed gently and incubated for $15 \mathrm{~min}$ at room temperature and protected from light, 500uL of 1X Add 500uL of 1X Binding Buffer. Immediately detect the FITC fluorescence level in the FITC channel and the PI fluorescence level in the PE channel according to the recommended method of the kit.Data analysis was done using FlowJo VX.

\section{Real time quantitative PCR}


After 7 days of cell culture, the positive electrode, negative electrode and control group cells were collected. The total RNA was extracted by simplyp total RNA extraction kit and reverse transcribed into cDNA. The expressions of osteocalcin, osterix and osteonectin were detected by real-time quantitative PCR. The experiment was repeated three times, with GAPDH as the internal reference and the relative expressions of osteocalcin, osterix and osteonectin were calculated by $2-\Delta \Delta \mathrm{Ct}$ method.The primers sequence used as follows(Table 1).

Table 1 Primers used in Real time quantitative PCR

\begin{tabular}{lc}
\hline Primer gene & \multicolumn{1}{c}{ Sequence $\left(5^{\prime}-3^{\prime}\right)$} \\
\hline Oxterix & Forward:5, -AGGTCTGATGGGACAGAGTGA-3, \\
& Reverse:5, - GGGCTGAAAGGTCAGCGTAT-3, \\
osteocalcin & Forward:5' -CCTTCATGTCCAAGCAGGA-3, \\
& Reverse:5, - GGCGGTCTTCAAGCCATAC-3, \\
osteonectin & Forward:5' - GATGGGATGTTGTCCCTTCCC-3, \\
& Reverse:5, - GAGACACTGGGTAGTGCAGG-3, \\
GAPDH & Forward:5, - GGCTGCCCAGAACATCAT-3, \\
& Reverse:5' - CGGACACATTGGGGGTAG-3, \\
\hline
\end{tabular}

\section{Surgery and Grouping}

Rabbits (New Zealand white rabbits, male, weigh 2.5-3Kg, $\mathrm{n}=12$ ) were purchased from a commercial vendor (Animal Certificate No.: SCXK (Yu )2021-0010). This study was conducted with the approval of the Experimental Animal Ethics Committee of Children's Hospital of Chongqing Medical University, China (20201112004), and carried out in accordance to the ARRIVE guidelines. Preoperatively, fasting with food and water, $3 \%$ pentobarbital sodium was administered intravenously at a dose of $1 \mathrm{ml} / \mathrm{kg}$ along the ear margin for anesthesia. The rabbits were placed supine on the operating table, the right hind foot was shaved, a sterile towel was laid down and the rabbits were disinfected with iodophor 3 times, the skin was cut longitudinally with a scalpel at the middle of the 1st and 3rd phalanx, the muscle and fascia were separated and the phalanx was exposed. At the middle part of the toe, the toe bone was severed with a bone saw, resulting in a complete fracture of the toe bone. The excess bone debris was cleaned up and the fracture site was fixed with $0.8 \mathrm{~mm}$ kerf pins. The wounds were disinfected with iodophor and plastered for external fixation (Fig.2). The prepared animal models were randomly divided into two groups (experimental group and control group), with six animals in each group. The experimental group was the DC stimulation group. Immediately after modelling, the negative DC electrode was connected to 
the 1st toe pin and the positive electrode was connected to the 3 rd toe pin, and the animals were continuously electrically stimulated with a direct current of $10 \mathrm{uA}$.

\section{Radiological assessment}

All rabbits were photographed at the fracture site at 3 time points, 1 day, half a month and 1 month after modelling, to observe fracture healing and the position of the kerf pins, and to follow up on fracture line changes and bone scab formation after the fracture.

\section{Histological analysis}

At month-1, animals were euthanized. Toes bones were dissected and fixed in $4 \%$ paraformaldehyde, then decalcified in JYBL- $\triangle$ decalcifying solution (Solarbio, catelog\#G2470). Bones were paraffin-embedded and sectioned into 5um slices, then HE staining and Goldner's trichrome staining were performed.

\section{Statistics}

The results were statistically analysed using SPSS (version 20.0) and GraphPad Prism V.8.00. Data are expressed as mean \pm standard deviation using t-test and one-way ANOVA except for histological data. Stained sections were photomicrographed and histomorphometrically analyzed using Aperio ImageScope v12.1.0.5029 (Leica, USA). p<0.05 is considered a statistically significant difference.

\section{Results}

\section{Effects of DC polarity on cell proliferation}

In the mc3t3-e1 cell count after 24 hours of electrical stimulation, the number of cells decreased significantly with a live cell growth rate of $-7.4 \%$ for the positive electrode compared to $107 \%$ and $71 \%$ for the control and negative electrode groups, respectively. When electrical stimulation was applied for 48 hours, the growth rate of live cells was $-86.7 \%$ for the positive electrode, compared to $201 \%$ and $181 \%$ for the control and negative electrodes, respectively. Compared to the control and negative electrodes, there were significantly fewer cells around the positive electrode, and the difference was statistically significant $(P<0.05)$; there was no significant difference in cell proliferation between the negative electrode and the control $(P>0.05)$ (Fig.3A).

\section{Effects of DC polarity on cell apoptosis}

After $24 \mathrm{~h}$ of electrical stimulation, the apoptosis rate of cells at the positive and negative electrodes was not significantly different from the control group. After $48 \mathrm{~h}$ of electrical stimulation, the apoptosis rate of cells near the positive electrode attachment was significantly higher than that of the negative electrode and the control $(P<0.05)$ (Fig.3B).

Effects of DC polarity on osteocalcin, osterix and osteonectin expression 
The specific expression of osteocalcin, osterix and osteonectin in MC3T3-E1 cells was quantitatively detected by real-time PCR. Compared with the control group, the expression of the above genes decreased under the positive electrode $(P<0.05)$, but increased significantly under the negative electrode $(P<0.05)$ (Fig. 4).

\section{Radiological assessment}

The fracture line at the negative electrode connection disappeared and the fracture healed at 1 month, while the fracture healing at the positive electrode connection was poor, with the fracture line clearly visible and almost no bone scab formation. In the control group all cases had good healing of both fractures with disappearance of the fracture line (Fig.5).

\section{Histological analysis}

One month after fracture, HE staining showed that a large number of osteoblasts and osteoclasts infiltrated into the cartilage of the control group and the negative fracture group, forming a large number of bone trabeculae. The bone trabeculae were wider and tightly connected than those of the positive fracture group, while a large number of fibrous calluses were still formed in the positive fracture group, and even no osteoblasts and bone trabeculae were found in some areas (Fig.6). Goldner's three-color staining showed a large number of green mineralized bones in the control group and the negative electrode bone tissue, and there was still a large area of red-like bone in the positive electrode bone tissue, with a small amount of green mineralized bone (Fig. 6).

\section{Discussion}

After bone tissue injury, in the process of regeneration and remodeling, with the changes of physiological and environmental factors, it will constantly reshape the shape of bone and reconstruct bone matrix [7]. Therefore, the potential generated by the stress of collagen fibers in bone can promote bone reconstruction [8]. In the previous clinical research, we found that when two or more fractures occur at the same site at the same time, after metal internal fixation of the fracture site, one fracture heals smoothly, while other fractures have delayed union or nonunion. Reviewing the medical history of these cases, we can basically eliminate the common factors leading to fracture nonunion. However, when we remove the healed fracture, internal fixation can effectively promote the healing of the nonunion(Fig. 7). Studies have shown that when the fracture occurs, the electronegativity of the metaphysis becomes more negative, and the electronegativity of the whole fracture site also becomes negative, and the change of electronegativity is maintained until the fracture is healed [9]. When two fractures occur in the same part, they produce bone tissue repair potential respectively. Whether the local current will produce relatively positive and negative electrodes due to the potential difference has not been reported in the literature.

The purpose of this study was to observe the effect of DC positive and negative electrodes on osteoblast proliferation and fracture healing in vitro. Although there have been numerous previous studies on the effect of current on osteogenesis, the research mainly focuses on the role of promoting osteogenesis, and 
almost does not analyze the effects of different electrodes in the process of current stimulation $[6,10$, 11]. Studies have shown that the cell density near the electrode is significantly lower than that between the electrodes, and the cell density near the positive electrode is lower than that near the negative electrode [12]. This was also confirmed in our in vitro study. In the same voltage DC electric field, the proliferation of MC3T3-E1 cells near the positive electrode was significantly limited and had a time accumulation effect, and the apoptosis was more obvious with the extension of electrical stimulation time.

After fracture, osteoblasts proliferate into bone marrow and eventually differentiate into bone marrow mesenchymal cells [13]. Evidence shows that bone marrow mesenchymal stem cells and osteoblasts migrate towards the cathode due to their electrotaxis, while osteoclasts migrate towards the anode [14]. Our research mainly focused on the subsequent proliferation of osteoblasts. In order to better observe the proliferation of positive and negative electrode cells, we improved the electrical stimulation device of mobini and leppik et al. [6], so as to completely separate the cells near the positive and negative electrodes and facilitate statistical analysis. Although electrical stimulation has been mainly proved to improve the cell proliferation rate, there are also contrary findings, indicating that electrical stimulation can also reduce cell proliferation or has no effect on cell proliferation [15]. Our results showed that compared with the control group, the proliferation of positive electrode cells decreased and the proliferation of negative electrode cells had no effect in the electrical stimulation group. This is related to the increase of apoptosis near the positive electrode. The mechanisms of inhibition of cell proliferation by electrical stimulation include cell cycle arrest and intracellular $\mathrm{ca}^{2}+$ Influx and tumor suppressor protein up regulation. Electrical stimulation activated L-type calcium ${ }^{2}+$ Channels, when intracellular calcium ${ }^{2}+$ When the level is still at the normal physiological concentration, cell proliferation and apoptosis are not affected, and intracellular calcium ${ }^{2}+$ When the level exceeds the threshold of activating apoptosis, apoptosis increases [16].

Osteocalcin, Oxterix and osteonectin are important factors of osteoblast differentiation and bone formation, and are markers of late osteogenic differentiation [17-20]. The experimental results show that the expression of bone related genes in the positive electrode group is lower than that in the control group and the negative electrode group, and the expression of bone related genes in the negative electrode group is significantly higher than that in the control group, indicating that the positive electrode (positive charge) reduces the expression of bone related genes and regulates the level of related osteogenic pathways, which is not conducive to osteoblast osteogenesis. The negative electrode up regulates the expression of osteogenic related genes, which is conducive to promote the differentiation of osteoblasts into bone. Some studies have shown that the biophysical changes of electric field can also be triggered on the cell surface. The function of membrane proteins is affected by changing the charge distribution on biomolecules, such as enzyme activity ( $\mathrm{Na}+/ \mathrm{K}+$ ATPase and $\mathrm{Ca} 2+$ ATPase), membrane receptor complex and ion transport channel. When the current passes through the cathode, it reduces the oxygen concentration through Faraday reaction, increases the $\mathrm{pH}$ value and produces hydrogen peroxide. The reduction of oxygen concentration enhances the activity of osteoblasts [21]. The concentration of positive and negative ions in the cell culture medium should be completely consistent in our experiment. 
After continuous DC stimulation for 1 month, the fracture in the control group was completely healed, while the fracture at the negative electrode connection was healed and the fracture at the positive electrode connection was not healed in the experimental group. Histological results also showed that in the control group and the negative electrode junction, more callus was formed, the bone trabecula was thicker, and the bone calcification was obvious, while the callus at the positive electrode junction was not completely formed. In the traditional method of DC stimulation to promote fracture healing, the speed of fracture healing is also different due to the different placement of electrodes. When the cathode is placed at the fracture site, a better effect can be obtained. However, in the traditional experiment, when two fractures occur in the same part, the positive and negative electrodes are connected to the two fractures at the same time. They all place one end of the electrode at the fracture site and the other end of the electrode in the normal tissue.

In this experiment, we chose the phalange as the research site because in the bone structure of rabbits, the phalange can effectively simulate two long bones in the same part, while taking 1 and 3 phalanges as the research object is to avoid the interaction of factors secreted by the two fracture parts in the process of fracture healing. Of course, there are still defects in our research design. We regard the time of fracture healing in the control group as the end point of the study, and did not detect the formation of callus at different stages in the process of fracture healing. In the selection of current, only one current is selected, which may be suspected that different current stimuli will lead to different results. However, the purpose of this study is only to simply detect whether positive and negative electrodes (or positive and negative charges) will affect fracture healing, and the selected current is $10 \mathrm{uA}$, which is the minimum current required for tissue healing. Our results are positive. Positive electrodes significantly inhibit fracture healing.

\section{Conclusion}

This study shows that the positive electrode (positive charge) inhibits the proliferation of osteoblasts, down regulates the expression of osteocalcin, osteoblast specific genes, osteonectin and other osteogenic genes, and inhibits cell osteogenesis. Negative electrode up regulates osteogenesis related genes and promotes osteogenesis. After fracture, the fracture site with positive charge will have delayed healing or nonunion. The abnormal charge at the fracture site may be one of the causes of fracture nonunion.

\section{Declarations}

\section{Acknowledgements}

We thank Sun Qian and Lei Huiyang for their technical assistance in Surgical techniques.

\section{Author's contributions}


Ling He : Conceptualization, Methodology, Formal analysis, Resources, Writing - original draft, Writing review \& editing. Yingling Yao: Methodology, Resources Writing - review \& editing. Nan Wang : Resources, Writing - review \& editing. Guoxin Nan: Funding acquisition, Supervision, Writing - review \& editing.

\section{Funding}

This study received no direct funding from any third-party donor or funding institution in the public, commercial, or non-profit sectors.

\section{Availability of data and materials}

The datasets used and/or analyzed during the current study available from the corresponding author on reasonable request.

\section{Consent for publication}

Not applicable.

\section{CONFLICT OF INTEREST}

The authors declare that they have no competing interests.

\section{References}

1. Wildemann, B., Ignatius, A., Leung, F., Taitsman, L. A., Smith, R. M., Pesántez, R., Stoddart, M. J., Richards, R. G., \& Jupiter, J. B. (2021). Non-union bone fractures. Nature reviews. Disease primers, 7(1), 57. https://doi.org/10.1038/s41572-021-00289-8.

2. Hak, D. J., Fitzpatrick, D., Bishop, J. A., Marsh, J. L., Tilp, S., Schnettler, R., Simpson, H., \& Alt, V. (2014). Delayed union and nonunions: epidemiology, clinical issues, and financial aspects. Injury, 45 Suppl 2, S3-S7. https://doi.org/10.1016/j.injury.2014.04.002

3. Spadaro J. A. (1997). Mechanical and electrical interactions in bone remodeling.

Bioelectromagnetics, 18(3), 193-202.

4. Friedenberg, Z. B., Harlow, M. C., \& Brighton, C. T. (1971). Healing of nonunion of the medial malleolus by means of direct current: a case report. The Journal of trauma, 11(10), 883-885. https://doi.org/10.1097/00005373-197110000-00010.

5. Tan, Z., Havell, E. A., Orndorff, P. E., \& Shirwaiker, R. A. (2017). Antibacterial efficacy and cytotoxicity of low intensity direct current activated silver-titanium implant system prototype. Biometals: an international journal on the role of metal ions in biology, biochemistry, and medicine, 30(1), 113-125. https://doi.org/10.1007/s10534-017-9993-1.

6. Leppik, L., Bhavsar, M. B., Oliveira, K., Eischen-Loges, M., Mobini, S., \& Barker, J. H. (2019). Construction and Use of an Electrical Stimulation Chamber for Enhancing Osteogenic Differentiation 
in Mesenchymal Stem/Stromal Cells In Vitro. Journal of visualized experiments: JoVE, (143), 10.3791/59127. https://doi.org/10.3791/59127

7. S. Bumrerraj, J. L. Katz, S. -. You and M. Tabib-Azat, "High resolution studies of the electromechanical properties of bone during remodeling," Proceedings of the First Joint BMES/EMBS Conference. 1999 IEEE Engineering in Medicine and Biology 21st Annual Conference and the 1999 Annual Fall Meeting of the Biomedical Engineering Society (Cat. N, 1999, pp. 494 vol.1-, doi:

10.1109/IEMBS.1999.802572.

8. Wu, Xiao Gang, and Wei Yi Chen. "Experimental Study of Stress-Generated Potentials on Large Cattle Femur under Simulated Physiological Loading State." Applied Mechanics and Materials, vol. 29-32, Trans Tech Publications, Ltd., Aug. 2010, pp. 2549-2554. Crossref, doi:10.4028/www.scientific.net/amm.29-32.2549.

9. Friedenberg ZB, Harlow MC, Brighton CT. Healing of nonunion of the medial malleolus by means of direct current: a case report. J Trauma. 1971 Oct;11(10):883-5. doi: 10.1097/00005373-19711000000010.

10. Fonseca JH Junior, Bagne L, Meneghetti DH, Dos Santos GMT, Esquisatto MAM, de Andrade TAM, do Amaral MEC, Felonato M, Caetano GF, Santamaria M Junior, Mendonça FAS. Electrical stimulation: Complementary therapy to improve the performance of grafts in bone defects? J Biomed Mater Res B Appl Biomater. 2019 May;107(4):924-932. doi: 10.1002/jbm.b.34187. Epub 2018 Sep 28.

11. Zhu B, Li Y, Huang F, Chen Z, Xie J, Ding C, Li J. Promotion of the osteogenic activity of an antibacterial polyaniline coating by electrical stimulation. Biomater Sci. 2019 Nov 1;7(11):47304737. doi: 10.1039/c9bm01203f. Epub 2019 Sep 9.

12. Srirussamee K, Mobini S, Cassidy NJ, Cartmell SH. Direct electrical stimulation enhances osteogenesis by inducing Bmp2 and Spp1 expressions from macrophages and preosteoblasts. Biotechnol Bioeng. 2019 Dec;116(12):3421-3432. doi: 10.1002/bit.27142. Epub 2019 Sep 23.

13. Cottrell JA, Turner JC, Arinzeh TL, O'Connor JP. The Biology of Bone and Ligament Healing. Foot Ankle Clin. 2016 Dec;21(4):739-761. doi: 10.1016/j.fcl.2016.07.017.

14. Cortese B, Palamà IE, D'Amone S, Gigli G. Influence of electrotaxis on cell behaviour. Integr Biol (Camb). 2014 Sep;6(9):817-30. doi: 10.1039/c4ib00142g.

15. Leppik L, Oliveira KMC, Bhavsar MB, Barker JH. Electrical stimulation in bone tissue engineering treatments. Eur J Trauma Emerg Surg. 2020 Apr;46(2):231-244. doi: 10.1007/s00068-020-01324-1. Epub 2020 Feb 20. PMID: 32078704

16. Love MR, Palee S, Chattipakorn SC, Chattipakorn N. Effects of electrical stimulation on cell proliferation and apoptosis. J Cell Physiol. 2018 Mar;233(3):1860-1876. doi: 10.1002/jcp.25975. Epub 2017 Jun 6.

17. Mizokami, A., Kawakubo-Yasukochi, T., \& Hirata, M. (2017). Osteocalcin and its endocrine functions. Biochemical pharmacology, 132, 1-8. https://doi.org/10.1016/j.bcp.2017.02.001

18. Liu, Q., Li, M., Wang, S., Xiao, Z., Xiong, Y., \& Wang, G. (2020). Recent Advances of Osterix Transcription Factor in Osteoblast Differentiation and Bone Formation. Frontiers in cell and 
developmental biology, 8, 601224. https://doi.org/10.3389/fcell.2020.601224

19. Rosset, E. M., \& Bradshaw, A. D. (2016). SPARC/osteonectin in mineralized tissue. Matrix biology: journal of the International Society for Matrix Biology, 52-54, 78-87.

https://doi.org/10.1016/j.matbio.2016.02.001

20. Zhu, Y. S., Gu, Y., Jiang, C., \& Chen, L. (2020). Osteonectin regulates the extracellular matrix mineralization of osteoblasts through P38 signaling pathway. Journal of cellular physiology, 235(3), 2220-2231. https://doi.org/10.1002/jcp.29131

21. Hammerick, K. E., Longaker, M. T., \& Prinz, F. B. (2010). In vitro effects of direct current electric fields on adipose-derived stromal cells. Biochemical and biophysical research communications, 397(1), 12-17. https://doi.org/10.1016/j.bbrc.2010.05.003

\section{Figures}
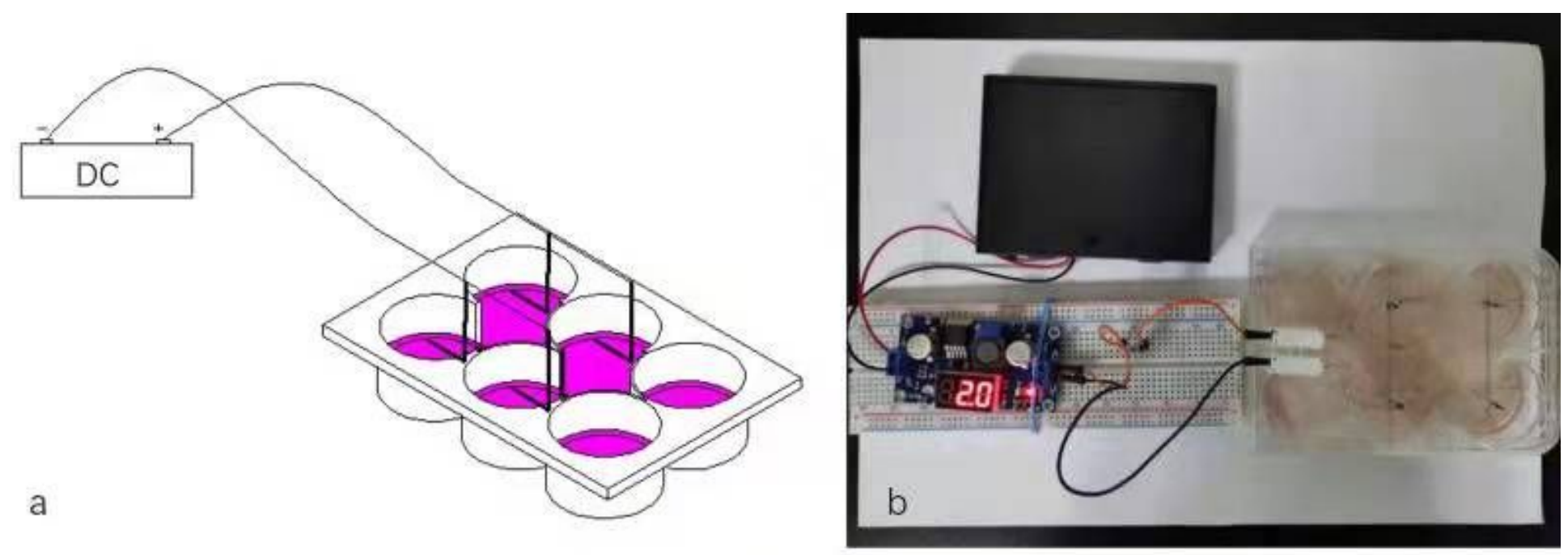

Figure 1

EStim cell culture chamber. 

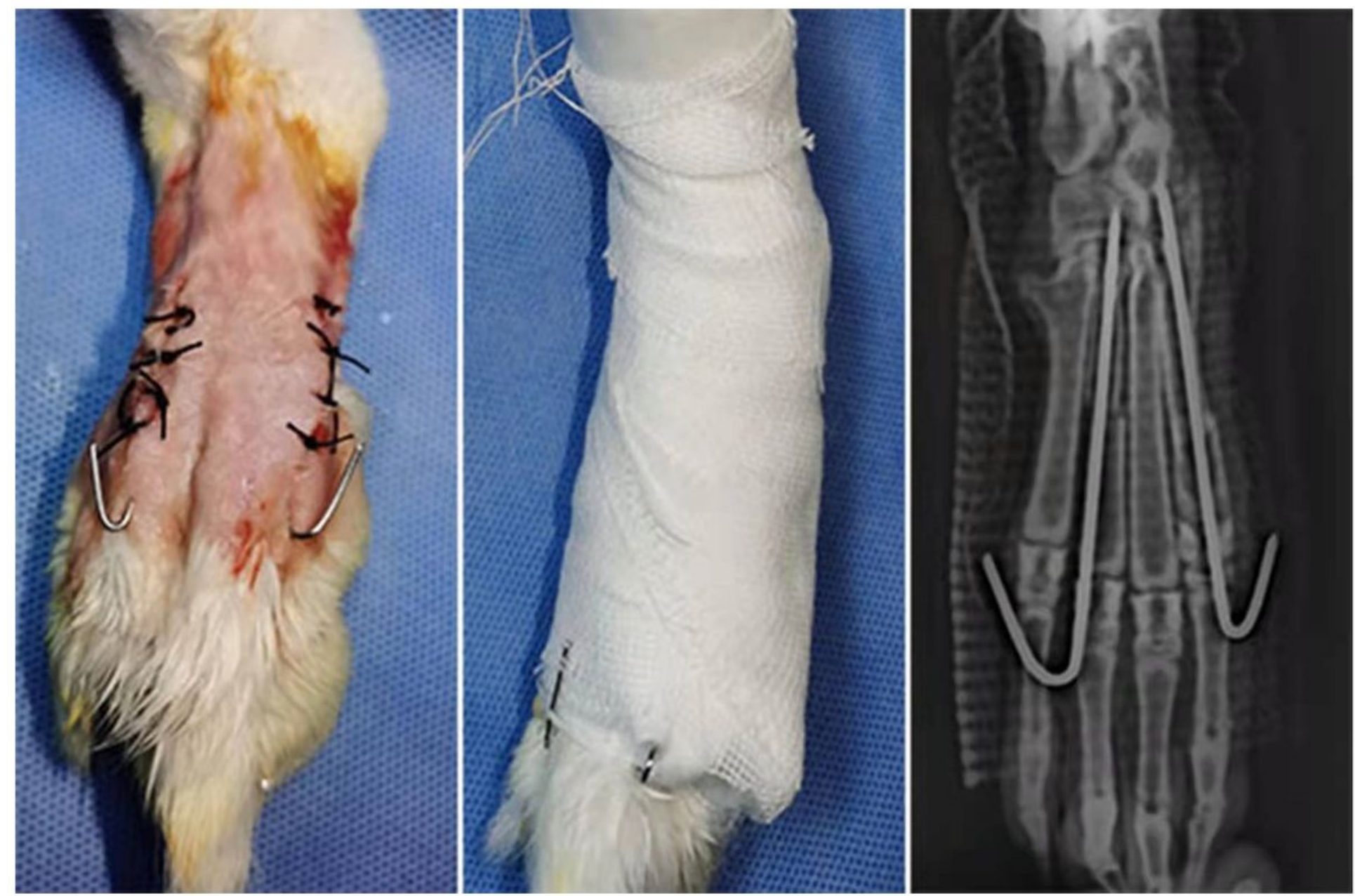

Figure 2

Double fracture model of the toe bone of the New Zealand great white rabbit.
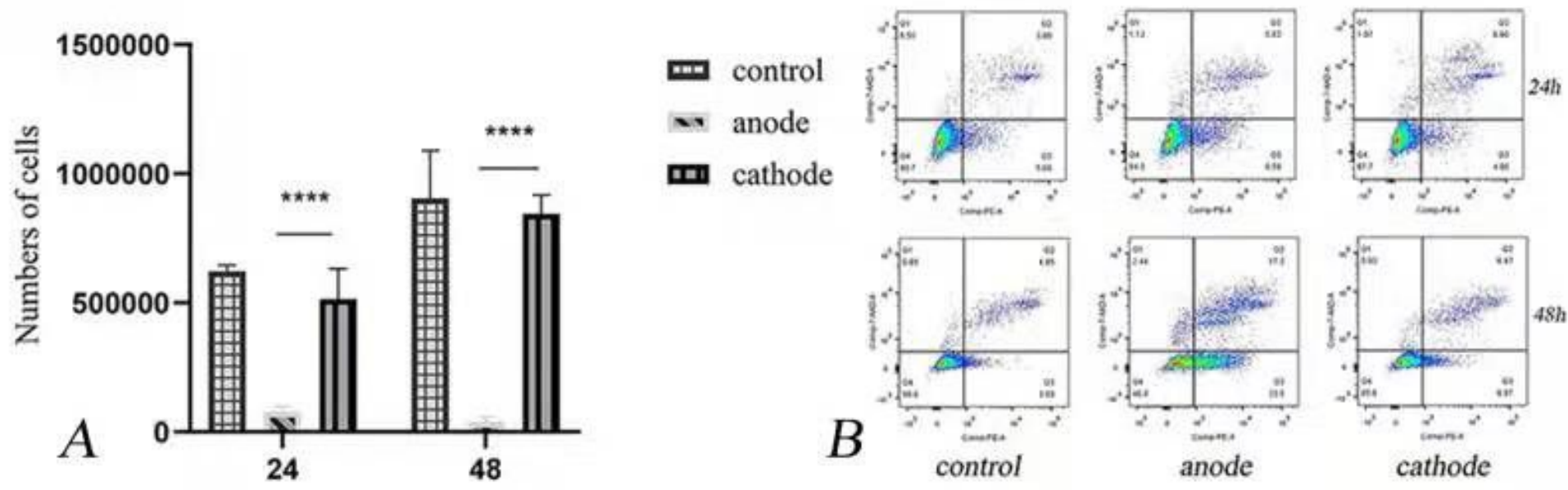

\section{Figure 3}

A.: DC stimulation 24 and 48 hours positive electrode, negative electrode and control cell counts. 
$\mathrm{B} \square \mathrm{Apoptosis}$ of cells near the positive and negative electrodes in the control and electrical stimulation groups at 24 and 48 hours.
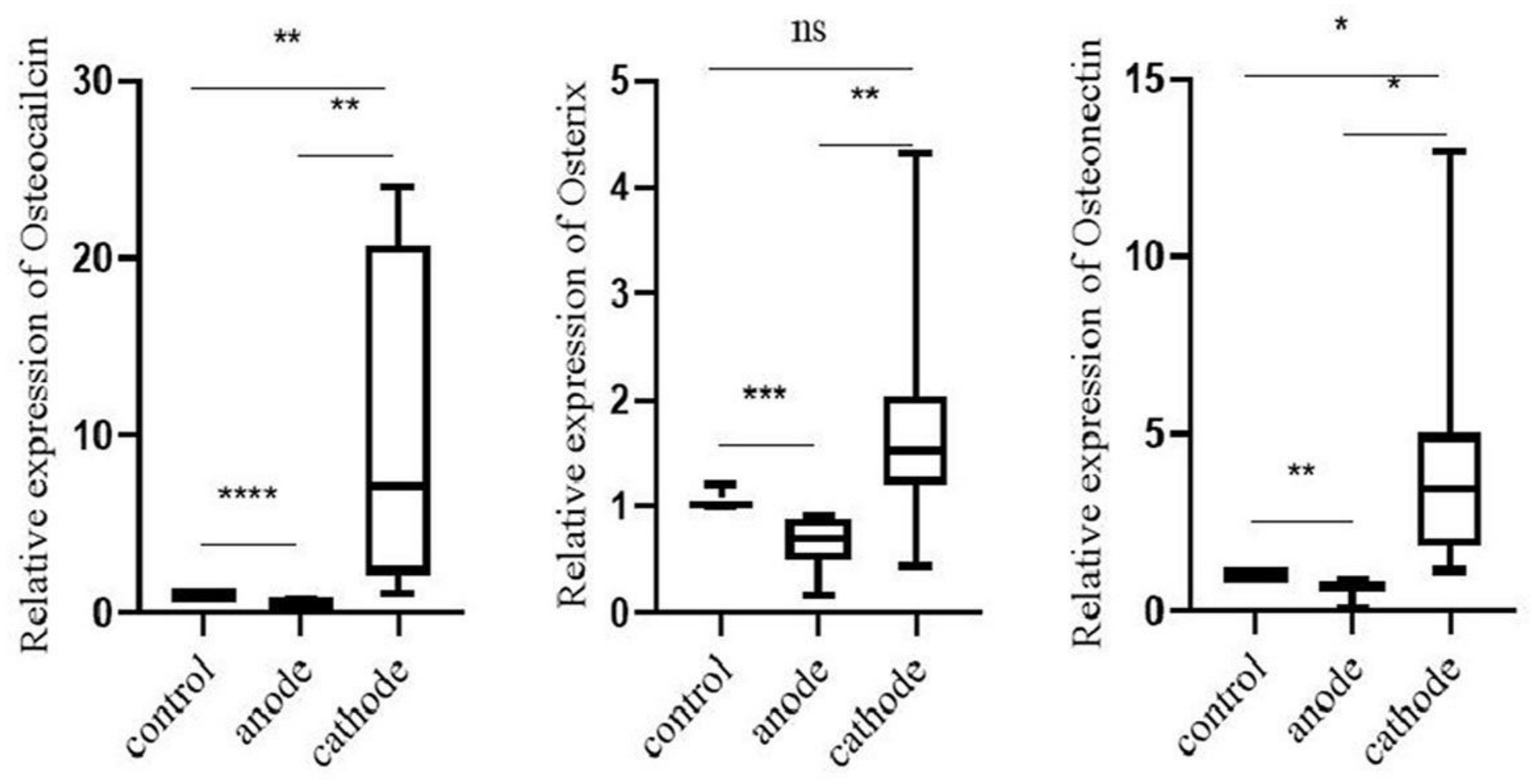

Figure 4

The expression levels of osteocalcin, osterix and osteonectin in MC3T3-E1 cells of different electrodes

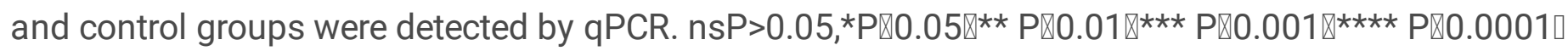

\section{Figure 5}

$A$ and $B$ are toe $D R$ images 1 day after fracture; $C$ is toe $D R$ image 1 month after surgery in the control group, where the fracture line disappeared; $D$ is toe $D R$ image 1 month after surgery in the electrical stimulation group, where the fracture line indicated by the arrow is obvious $(N \geq 3)$.

\section{Figure 6}

Typical tissue images stained with hematoxylin eosin and Goldner's trichrome 1 month after surgery. HE staining of bone tissue in controls $\mathrm{A} 1, \mathrm{C} 1, \mathrm{E} 1, \mathrm{G} 1$ and $\mathrm{B} 1$ and $\mathrm{F} 1$ at the negative electrode connection shows a large number of trabeculae formation with no gap between the tissues. Bone tissue D1 and H1 at the positive electrode connection shows a small amount of trabecular formation and some areas have neither trabeculae nor osteocytes. Goldner staining of bone tissue in controls A2, C2, E2, G2 and at the negative electrode connections B2 and F2 shows large areas of green mineralized bone that is connected 
in sheets with only a small amount of bone-like material and no gap between the tissues. Bone tissue at the positive electrode junction D2 and $\mathrm{H} 2$ showed a large area of red osteoid at the positive electrode fracture with very little green mineralised bone $(\mathrm{N} \geq 3)$.

\section{Figure 7}

(a) Ulna not healing after 6 months of internal fixation of ulnar and radial fractures; (b) removal of internal fixation of ulnar and radial bones and fixation of ulna with Kirschner pins; (c) ulnar fracture healing after 6 weeks; ( $d, e, f)$ second and third phalanges not healing after 3 months of Kirschner pin fixation. The second and third phalanges healed within 8 weeks after removal of internal fixation at the healed fracture site. 